\title{
Casca de café em dietas para novilhas leiteiras: consumo, digestibilidade e desempenho
}

\author{
Alexandre Lima de Souza², Rasmo Garcia ${ }^{3}$, Fernando Salgado Bernardino ${ }^{4}$, José Maurício \\ de Souza Campos ${ }^{3}$, Sebastião de Campos Valadares Filho ${ }^{3}$, Luciano da Silva Cabral ${ }^{5}$, \\ Kátia Fernanda Gobbi ${ }^{4}$
}

\author{
${ }^{1}$ Projeto financiado pela Fundação de Amparo à Pesquisa do Estado de Minas Gerais (FAPEMIG). \\ 2 Curso de Zootecnia/ICEN/UFMT \\ ${ }^{3}$ Departamento de Zootecnia/UFV \\ 4 Zootecnista, MS, DZO/UFV. \\ ${ }^{5}$ Departamento de Zootecnia/FAMEV/UFMT.
}

\begin{abstract}
RESUMO - Avaliaram-se o consumo, a digestibilidade aparente e o desempenho de novilhas recebendo dietas contendo diferentes teores de casca de café $(0 ; 8,75 ; 17,5$ e 26,25\% da MS da ração concentrada) em substituição ao milho. Foram utilizadas 24 novilhas Holandês-Zebu, distribuídas em um delineamento em blocos casualizados. As dietas foram isonitrogenadas, com $15,5 \%$ de $\mathrm{PB}$, constituídas de $60 \%$ de pré-secado de tifton 85 e $40 \%$ de ração concentrada na MS. Os consumos de MS, MO, PB, CT e FDN não foram alterados, registrando-se valores médios de 6,$75 ; 6,23 ; 1,04 ; 5,01$ e 3,11 kg/dia, respectivamente Os consumos de CNF e NDT observados reduziram linearmente com a adição de casca de café. As digestibilidades da MS, MO, PB, CT, FDN e CNF e a concentração de NDT das dietas diminuíram linearmente com a adição de casca de café. O ganho de peso decresceu linearmente com a inclusão de casca de café na dieta, estimando-se queda de $6,94 \mathrm{~g}$ de PV/unidade porcentual de casca de café adicionada ao concentrado. Todavia, a inclusão deste resíduo em até $17,5 \%$ de substituição ao milho da ração concentrada $(7,0 \%$ na MS da dieta) pode ser considerada benéfica, pois os ganhos médios diários observados foram próximos aos obtidos com a inclusão de 0,0 e $8,75 \%$ de casca de café na ração concentrada.
\end{abstract}

Palavras-chave: composição química, conversão alimentar, ganho de peso, resíduo agroindustrial

\section{Coffee hulls in dairy heifers diet: intake, digestibility, and production}

\begin{abstract}
The objective of this trial was to investigate the effects of partially replacing ground corn with coffee hulls $(0.0,8.75,17.5$ and $26.25 \%$ of concentrate DM) on nutrient intake, apparent total tract digestibility, and daily weight gain of dairy heifers. Twenty-four Holstein x Zebu heifers were assigned to a randomized complete block design with four treatments and six replicates. Diets were isonitrogenous $(15.5 \% \mathrm{CP})$ and contained $60 \%$ of Tifton- 85 haylage and $40 \%$ of concentrate. Intakes of dry matter $(6.75 \mathrm{~kg} /$ day $)$, organic matter $(6.23 \mathrm{~kg} /$ day $), \mathrm{CP}(1.04 \mathrm{~kg} /$ day), total carbohydrates $(5.01$ $\mathrm{kg}$ /day), and neutral detergent fiber $(3.11 \mathrm{~kg}$ /day) were not changed whereas those of nonfiber carbohydrates (NFC) and total digestible nutrients (TDN) decreased linearly by inclusion of coffee hulls in the diet. Apparent total tract digestibilities of dry matter, organic matter, CP, total carbohydrates, neutral detergent fiber, NFC, and TDN all decreased linearly by partially replacing ground corn with coffee hulls. Daily weight gain decreased $6.94 \mathrm{~g}$ per each percentage unit of coffee hulls added to the diet. However, inclusion of up to $17.5 \%$ of coffee hulls $(7.0 \%$ of the diet DM) maintained daily weight gain similar to those obtained with 0.0 and $8.75 \%$ of coffee hulls in the concentrate.
\end{abstract}

Key Words: agroindustrial residue, chemical-bromatologic composition, feed conversion, weight gain

\section{Introdução}

Tanto nos sistemas de produção de leite a pasto como em confinamento, as novilhas desempenham papel fundamental na continuidade do processo produtivo. É a partir delas, produzidas na própria fazenda ou adquiridas de outros rebanhos, que ocorre, na maioria das vezes, o melhoramento genético dos plantéis.
Apesar de sua importância na atividade leiteira, as novilhas, geralmente, são os animais que recebem menos atenção do produtor. $\mathrm{O}$ inadequado desenvolvimento das novilhas eleva a idade ao primeiro parto, determinando maior número de animais que não estão produzindo leite. Entre os fatores que contribuem para esta situação, os gastos com alimentação, principalmente os elevados custos dos alimentos concentrados, são seguramente os 
maiores responsáveis pelo baixo nível nutricional dos animais.

$\mathrm{Na}$ tentativa de viabilizar um plano nutricional que melhore os índices produtivos dos rebanhos e que, ao mesmo tempo, contribua para a redução de custos, diversas alternativas têm sido propostas, entre elas, a utilização de resíduos da agroindústria, que, em razão das características singulares na composição bromatológica, na forma física, na disponibilidade e no custo, apresentam diferenças quanto ao potencial de utilização na nutrição de ruminantes.

A cafeicultura destaca-se por ser uma atividade agrícola que origina elevado volume de resíduos. Dos resíduos provenientes do beneficiamento do grão de café, a casca obtida pelo método via seca, em virtude da disponibilidade e das características químico-bromatológicas, apresenta grande potencial para utilização na alimentação de ruminantes.

Dados da literatura comprovam que a casca de café pode apresentar variações significativas em sua composição, especialmente nos teores de PB, FDN e lignina (Barcelos et al., 1997; Vilela, 1999; Baião, 2002). Ao descrever a composição química da casca de café, Souza et al. (2004) verificaram valores, na MS, de $6,9 \%$ de $\mathrm{PB}$ (contendo $24,4 \%$ na forma de NIDA), $\mathrm{FDN}(59,4 \%)$, lignina (12\%), CNF (30,1\%), EE $(1,8 \%)$ e fibra em detergente ácido indigestível $(37,7 \%)$, enquanto Barcelos et al. (2001) descreveram valor médio de $0,87 \%$ de cafeína na casca de café de três variedades analisadas. Ao adicionarem $0 ; 2,5 ; 5,0 ; 7,5$ e $10 \%$ de casca de café na MS da dieta de ovinos, em substituição ao milho da ração concentrada, Souza et al. (2004) não verificaram alterações no consumo e na digestibilidade da MS e dos nutrientes da dieta.

Considerando o volume de casca de café anualmente gerado, a possibilidade de inclusão deste resíduo como parte da dieta de novilhas de rebanhos leiteiros e a carência de resultados de pesquisas, conduziu-se este estudo objetivando avaliar o consumo, a digestibilidade aparente, e o desempenho de novilhas leiteiras consumindo dietas contendo diferentes níveis de casca de café em substituição ao milho na ração concentrada.

\section{Material e Métodos}

O experimento foi conduzido na Unidade de Ensino, Pesquisa e Extensão em Gado de Leite do Departamento de Zootecnia da Universidade Federal de Viçosa, no período de 14 de fevereiro a 18 de maio de 2001.

Foram utilizadas quatro novilhas 7/8, quatro 15/16 e 16 puras por cruza Holandês-Zebu com peso inicial de 201,21 $\pm 60,13 \mathrm{~kg}$. O delineamento experimental adotado foi o de

blocos casualizados, com seis blocos, formados por quatro animais conforme o peso vivo. Uma vez que as novilhas 7/8 e 15/16 Holandês-Zebu foram selecionadas com peso vivo aproximado, todos os blocos foram constituídos por animais de mesmo grau de sangue.

As novilhas foram alojadas em baias individuais com $8 \mathrm{~m}^{2}$, cimentadas, dotadas de comedouro, bebedouro e uma área para repouso dos animais, na qual utilizou-se cepilho de madeira. As baias eram limpas diariamente e as camas trocadas sempre que necessário. No início do período de adaptação, os animais receberam $1,0 \mathrm{~mL} / 50 \mathrm{~kg}$ PV do complexo vitamínico ADE e foram tratados contra endo e ectoparasitas.

Os tratamentos foram constituídos de quatro níveis casca de café $(0 ; 8,75 ; 17,5$ e $26,25 \%)$, com base na MS, em substituição ao fubá de milho da ração concentrada, correspondendo aos teores de $0 ; 3,5 ; 7,0$ e 10,5\% na MS da dieta total. Os animais receberam quatro dietas completas contendo $60 \%$ de pré-secado de capim-tifton 85 e $40 \%$ de concentrado. As dietas, isonitrogenadas, com aproximadamente $15,5 \%$ de $\mathrm{PB}$, foram formuladas conforme recomendações do NRC (1989) e fornecidas ad libitum duas vezes ao dia, às $7 \mathrm{e} 17 \mathrm{~h}$, de modo a permitir sobras de $5 \mathrm{a}$ $10 \%$ da MS. A ração concentrada foi misturada com o volumoso no momento do fornecimento da alimentação. A composição percentual dos ingredientes das dietas encontra-se na Tabela 1 .

A casca de café foi adquirida de indústria beneficiadora, na qual o processamento do grão é por via seca. Na casca de café contêm a polpa, a mucilagem e o pergaminho ou casquinha (Bártholo, 1989). Para permitir uma mistura mais homogênea na ração concentrada, a casca de café foi

Tabela 1 - Composição percentual dos ingredientes da dieta (\% da MS)

Table 1 - Ingredient composition of diets (\% of DM)

\begin{tabular}{|c|c|c|c|c|}
\hline \multirow[t]{2}{*}{$\begin{array}{l}\text { Ingrediente } \\
\text { Ingredient }\end{array}$} & \multicolumn{4}{|c|}{$\begin{array}{c}\text { Dieta }^{1} \\
\text { Diet }\end{array}$} \\
\hline & 0 & 8,75 & 17,5 & 26,25 \\
\hline $\begin{array}{l}\text { Pré-secado de } \\
\text { capim-Tifton- } 85\end{array}$ & 60,0 & 60,0 & 60,0 & 60,0 \\
\hline Tifton-85 haylage & & & & \\
\hline $\begin{array}{l}\text { Farelo de soja } \\
\text { Soybean meal }\end{array}$ & 7,82 & 7,78 & 7,68 & 7,68 \\
\hline $\begin{array}{l}\text { Milho } \\
\text { Ground corn }\end{array}$ & 30,36 & 26,9 & 23,5 & 20,0 \\
\hline $\begin{array}{l}\text { Casca de café } \\
\text { Coffee hulls }\end{array}$ & 0,0 & 3,5 & 7,0 & 10,5 \\
\hline $\begin{array}{l}\text { Suplemento mineral } \\
\text { Mineral supplement }\end{array}$ & 1,82 & 1,82 & 1,82 & 1,82 \\
\hline
\end{tabular}


Tabela 2 - Composição química do pré-secado, da casca de café e das rações concentradas Table 2 - Chemical composition of Tifton-85 haylage, coffee hulls and concentrate

\begin{tabular}{|c|c|c|c|c|c|c|}
\hline \multirow[t]{2}{*}{ Itens } & \multirow[t]{2}{*}{$\begin{array}{c}\text { Pré-secado de capim-tifton- } 85 \\
\text { Tifton- } 85 \text { haylage }\end{array}$} & \multirow[t]{2}{*}{$\begin{array}{l}\text { Casca de café } \\
\text { Coffee hulls }\end{array}$} & \multicolumn{4}{|c|}{$\begin{array}{l}\text { Concentrado } \\
\text { Concentrate }^{1}\end{array}$} \\
\hline & & & 0 & 8,75 & 17,5 & 26,25 \\
\hline $\mathrm{MO}^{2}(O M)$ & 91,4 & 92,9 & 93,6 & 92,9 & 92,3 & 91,7 \\
\hline $\mathrm{PB}^{2}(C P)$ & 16,5 & 8,6 & 13,7 & 13,7 & 13,5 & 14,1 \\
\hline $\mathrm{NIDN}^{3}$ (NDIN) & 30,7 & 31,6 & 5,1 & 6,8 & 9,2 & 10,1 \\
\hline $\mathrm{CT}^{2}(T C)$ & 73,3 & 83,5 & 75,6 & 75,3 & 75,2 & 74,6 \\
\hline $\mathrm{FDN}^{2}(N D F)$ & 69,2 & 58,5 & 10,6 & 14,4 & 18,5 & 22,4 \\
\hline $\mathrm{FDNcp}^{2}\left(N D F_{a p}\right)$ & 62,8 & 53,4 & 9,7 & 13,1 & 16,7 & 20,1 \\
\hline $\mathrm{CNF}^{2}(N F C)$ & 10,5 & 30,1 & 65,9 & 62,2 & 58,5 & 54,5 \\
\hline $\mathrm{FDA}^{2}(A D F)$ & 31,4 & 45,3 & 3,6 & 7,0 & 11,2 & 15,2 \\
\hline $\mathrm{FDAI}^{2}(A D F I)$ & 9,4 & 35,8 & 0,8 & 3,6 & 6,4 & 10,9 \\
\hline
\end{tabular}

triturada no mesmo moinho, com a mesma peneira, utilizado na moagem do milho. A composição bromatológica do volumoso, da casca de café e das rações concentradas encontra-se na Tabela 2.

O período experimental compreendeu 10 dias de adaptação e 84 dias de coleta de dados, subdivididos em três períodos de 28 dias. As sobras foram coletadas e pesadas individualmente duas vezes por semana, quando também foram amostrados os alimentos, posteriormente armazenados em freezer. Ao final de cada período de 28 dias, essas amostras foram misturadas, elaborando-se uma amostra composta por animal. Os animais foram pesados após jejum de 14 horas no início e final de cada período de 28 dias. Durante o período de jejum, os animais tiveram livre acesso à água.

A coleta de amostra de fezes para determinação da digestibilidade dos nutrientes foi realizada diretamente no reto dos animais, sempre às 8,12 e 16 h do $16^{\circ}, 18^{\circ}$ e $20^{\circ} \underline{o}$ dias, respectivamente, do terceiro período experimental. A estimativa da excreção fecal foi feita utilizando-se a fibra em detergente ácido indigestível (FDAI) como indicador interno, conforme (Cochran et al., 1986), com algumas alterações. Neste procedimento, as amostras de alimentos, sobras e fezes foram colocadas em sacos de digestibilidade Ankon (Filter bag F57) e incubadas no rúmen por um período de 144 horas. O material remanescente da incubação foi previamente lavado com água e submetido à extração com detergente ácido, considerando-se seu resíduo FDAI.
As amostras do pré-secado, da casca de café e das sobras e fezes foram previamente secas em estufas de ventilação forçada a $60^{\circ} \mathrm{C}$, durante 72 horas. Em seguida, foram homogeneizadas e processadas em moinho tipo Willey, utilizando-se peneira de $1 \mathrm{~mm}$. As análises de MS, MO, compostos nitrogenados totais, FDN, FDA, lignina e EE, NIDN e NIDA foram realizadas segundo procedimentos descritos por Silva \& Queiroz (2002). Os de CT foram calculados segundo Sniffen et al. (1992): $\mathrm{CT}=100-(\% \mathrm{~PB}+\% \mathrm{EE}+$ $\%$ Cinzas), enquanto os de $\mathrm{CNF}$, pela fórmula $\mathrm{CNF}=\mathrm{CT}-\mathrm{FDN}$.

Os nutrientes digestíveis totais estimados $\left(\mathrm{NDT}_{\mathrm{EST}}\right)$ dos alimentos, das rações concentradas e das dietas totais, foram estimados conforme equações de Weiss et al. (1992), utilizadas pelo NRC (2001). Nestas equações, para efeito do processamento físico (PF) do volumoso, da casca de café e do concentrado sobre a digestibilidade dos carboidratos não fibrosos foi considerada $\mathrm{PF}=1$.

Os valores de nutrientes digestíveis totais foram determinados para as diferentes dietas pela equação:

$$
\mathrm{NDT}=\mathrm{PBD}+\mathrm{EED} \times 2,25+\mathrm{FDND}+\mathrm{CNFD}
$$

em que $\mathrm{PBD}=$ proteína bruta digestível; $\mathrm{EED}=$ extrato etéreo digestível; FDND = fibra em detergente neutro digestível; CNFD = carboidratos não-fibrosos digestível.

Os resultados foram submetidos a análises de variância e de regressão, a 5\% de significância, utilizando-se o programa SAEG, versão 7.1 (UFV, 1997). A escolha do melhor modelo foi feita com base no coeficiente de determinação e na significância dos coeficientes de regressão, utilizando-se o teste " $\mathrm{t}$ " de Student, a 5\% de probabilidade. 


\section{Resultados e Discussão}

Os valores de fibra em detergente neutro e proteína bruta da casca de café (Tabela 2) foram inferiores aos de 67,6 e de 11,8 encontrados, respectivamente, por Oliveira et al. (2001). A concentração de nutrientes digestíveis totais $\left(\mathrm{NDT}_{\mathrm{EST}}\right)$ da casca de café $(44,9 \%)$ estimada a partir da composição bromatológica, de acordo as equações descritas pelo NRC (2001), foi 9, 1 pontos percentuais inferior ao valor de $\mathrm{NDT}_{\text {EST }}$ encontrado por Baião (2002). Grande parte desta diferença entre os valores de NDT estimados para a casca de café pode ser explicada pela variação na concentração de FDN e lignina constatada em diferentes pesquisas (Barcelos et al., 1997; Vilela, 1999; Souza et al., 2002).

Os valores médios relativos aos consumos diários de MS, MO, PB, EE, CT, FDN, CNF eNDT, com suas respectivas equações de regressão, são apresentados na Tabela 3. Não houve efeito $(\mathrm{P}>0,05)$ dos níveis de casca de café sobre os consumos diários de MS e MO, expressos em kg/dia e em $\%$ do PV, obtendo-se valores médios de 6,75 e 6,23 kg e de 2,81 e 2,59\% PV para essas variáveis. Em algumas pesquisas, tem-se relatado que a inclusão de resíduos do beneficiamento do grão de café, como a polpa, na dieta de bovinos pode reduzir o consumo de MS, como resultado da presença de compostos fenólicos neste resíduo (Vargas et al., 1982), o que não foi constatado nesta pesquisa e em outros experimentos realizados no Brasil (Barcelos et al., 1997; Vilela, 1999; Baião, 2002; Souza et al., 2004).
Talvez, a presença de compostos fenólicos na casca de café seja fator limitante quando este resíduo na dieta está presente em níveis elevados ou em substituição aos alimentos volumosos. Em situações cujo objetivo é incluir a casca de café em substituição a alimentos concentrados, provavelmente os baixos valores de PB e energia disponíveis são os principais fatores limitantes. Não foi observada diferença $(\mathrm{P}>0,05)$ na ingestão de $\mathrm{PB}$ com a adição de casca de café na ração concentrada, o que pode ser atribuído à ausência de efeito dos teores de casca sobre o consumo de MS e ao fato de as dietas terem sido isonitrogenadas.

O consumo médio diário de MS da casca de café foi de $0,228,465$ e $706 \mathrm{~g}$ para as dietas contendo, respectivamente, $0,8,75 ; 17,5 ;$ e $26,25 \%$ de casca na MS do concentrado, que, por sua vez, corresponderam aos níveis de $0 ; 3,5 ; 7,0 ;$ e 10,5\% de casca de café na MS da dieta. Apesar de este resíduo apresentar teor de FDN de 58,5\%, portanto, bem superior ao valor de $10,7 \%$ observado no milho (Valadares Filho et al., 2001), a análise de regressão não detectou efeito $(P>0,05)$ dos níveis de casca de café sobre os consumos diários de CT e FDN, quando expressos em $\mathrm{kg} /$ dia e \% PV (Tabela 3). Todavia, para o nível de significância $(\mathrm{P}<0,10)$, observou-se aumento no consumo de FDN quando expresso em \%PV, conforme a equação de regressão: $\hat{Y}=1,121-0,008 \mathrm{X}\left(\mathrm{r}^{2}=0,94\right)$, estimando-se acréscimo de $0,008 \%$ por unidade percentual de casca de casca adicionada à ração concentrada.

Verificou-se redução linear $(\mathrm{P}<0,05)$ nos consumos médios de EE e CNF, observando-se valores de 1,69 e 16,77 g/unidade

Tabela 3 - Consumos médios diários de MS e dos nutrientes da dieta, de acordo com os níveis de casca de café na ração concentrada (com base na MS), coeficiente de variação (CV) e equações de regressão

Table 3 - Average intakes of DM and nutrients in response to different coffee hulls levels on concentrate (DM basis), coefficient of variation (CV), and regression equations

\begin{tabular}{|c|c|c|c|c|c|c|}
\hline \multirow[t]{2}{*}{ Itens } & \multicolumn{4}{|c|}{$\begin{array}{l}\text { Dieta } \\
\text { Diet }\end{array}$} & \multirow{2}{*}{$\begin{array}{l}\text { CV } \\
\%\end{array}$} & \multirow[t]{2}{*}{$\begin{array}{l}\text { Equação de regressão } \\
\text { Regression equation }\end{array}$} \\
\hline & 0 & 8,75 & 17,5 & 26,25 & & \\
\hline \multicolumn{7}{|c|}{$\begin{array}{l}\text { Consumo }(\mathrm{kg} / \mathrm{dia}) \\
\text { Intake }(\mathrm{kg} / \text { day })\end{array}$} \\
\hline $\operatorname{MS}(D M)$ & 7,11 & 6,52 & 6,64 & 6,72 & 9,4 & $\hat{Y}=6,75$ \\
\hline MO $(O M)$ & 6,57 & 6,01 & 6,10 & 6,24 & 9,7 & $\hat{\mathrm{Y}}=6,23$ \\
\hline $\mathrm{CT}(T C)$ & 5,28 & 4,84 & 4,92 & 5,00 & 9,5 & $\hat{\mathrm{Y}}=5,01$ \\
\hline FDN $(N D F)$ & 3,10 & 2,94 & 3,11 & 3,28 & 9,3 & $\hat{\mathrm{Y}}=3,11$ \\
\hline $\mathrm{CNF}(N F C)$ & 2,18 & 1,90 & 1,81 & 1,72 & 10,2 & $\hat{\mathrm{Y}}=2,123-0,0168 \mathrm{X}\left(\mathrm{r}^{2}=0,91\right)$ \\
\hline NDT $(T D N)$ & 5,11 & 4,40 & 4,22 & 4,15 & 10,8 & $\hat{\mathrm{Y}}=4,929-0,0348 \mathrm{X}\left(\mathrm{r}^{2}=0,81\right)$ \\
\hline \multicolumn{7}{|c|}{$\begin{array}{c}\text { Consumo }(\% \mathrm{PV}) \\
\text { Intake }(\% B W)\end{array}$} \\
\hline MO $(O M)$ & 2,64 & 2,57 & 2,57 & 2,58 & 9,3 & $\hat{\mathrm{Y}}=2,59$ \\
\hline $\mathrm{CT}(T C)$ & 2,12 & 2,07 & 2,07 & 2,07 & 9,1 & $\hat{\mathrm{Y}}=2,08$ \\
\hline $\mathrm{FDN}(N D F)$ & 1,24 & 1,25 & 1,31 & 1,35 & 9,3 & $\hat{\mathrm{Y}}=1,29$ \\
\hline $\mathrm{CNF}(N F C)$ & 0,88 & 0,81 & 0,77 & 0,71 & 8,8 & $\hat{\mathrm{Y}}=0,876-0,0062 \mathrm{X}\left(\mathrm{r}^{2}=0,99\right)$ \\
\hline
\end{tabular}


percentual de casca adicionada no concentrado, respectivamente. O menor consumo destes nutrientes foi atribuído aos seus menores teores na casca de café (Tabela 2), em comparação aos 3,71\% de EE e de 73,40\% de amido encontrados no milho (Valadares Filho et al., 2001). Também houve redução no consumo de NDT $(\mathrm{P}<0,05)$, com queda de $34,8 \mathrm{~g}$ /unidade percentual de casca adicionada ao concentrado. $\mathrm{O}$ menor consumo de NDT pode ser atribuído à redução concomitante no consumo de $\mathrm{EE}$ e CNF, nutrientes de alta digestibilidade e elevado valor energético, em detrimento ao aumento no consumo dos constituintes da parede celular.

Os coeficientes de digestibilidade aparente da MS, MO, CT, FDN, CNF, PB e EE e a concentração de nutrientes digestíveis totais observada ( $\mathrm{NDT}_{\mathrm{OBS}}$ ) encontram-se na Tabela 4. Apesar de o consumo de MS não ter sido alterado, houve efeito linear $(\mathrm{P}<0,05)$ dos níveis de casca de café sobre os coeficientes de digestibilidade da MS, MO e PB estimando-se redução de 0,$395 ; 0,382 \mathrm{e} 0,355$ ponto percentual por unidade percentual de casca adicionada ao concentrado, respectivamente. A redução no consumo dos constituintes não-fibrosos, os quais apresentam disponibilidade rápida e praticamente completa no trato gastrintestinal dos ruminantes (Allen \& Mertens, 1987), associada às diferenças quantitativas entre os constituintes da parede celular do milho (Valadares Filho et al., 2001) e da casca de café (Tabela 2), foi considerada a principal causa da redução da digestibilidade da MS à medida que se adicionou casca de café às dietas. A redução na digestibilidade da PB foi associada aos elevados teores de NIDN e, principalmente, NIDA na casca.

Houve redução linear $(\mathrm{P}<0,05)$ nas digestibilidades dos CT, FDN e CNF com a adição de casca de café, estimando-se redução de 0,$387 ; 0,376$ e 0,282 ponto percentual por unidade percentual de casca adicionada ao concentrado, respectivamente. O decréscimo observado na digestibilidade dos CT refletiu em menor digestibilidade dos $\mathrm{CNF}$ e da fração fibro- sa. Por sua vez, a digestibilidade da fração FDN pode ter sido influenciada pelos altos teores de lignina na casca de café. A influência negativa da lignina sobre a digestibilidade da fração fibrosa da casca de café pode ser confirmada pelo alto teor de fibra em detergente ácido indigestível deste resíduo (Tabela 2), como observado por Souza et al. (2002), em estudos in vitro, que registraram baixa digestibilidade da FDN (média de 28,9\%).

A análise de regressão comprovou efeito linear $(\mathrm{P}<0,05)$ dos níveis de casca de café sobre os teores de NDT, estimando-se redução de 0,383 ponto percentual por unidade percentual de casca adicionada ao concentrado. A redução na digestibilidade aparente da MS e dos nutrientes, associada à menor ingestão de CNF, contribuiu para diminuição do desempenho dos animais, que, segundo Mertens (1994), depende do consumo de nutrientes digestíveis e metabolizáveis.

Os valores médios observados para o desempenho animal e a conversão alimentar encontram-se na Tabela 5. Pelo estudo da regressão polinomial, verificou-se efeito linear $(\mathrm{P}<0,05)$ dos teores de casca de café sobre o ganho médio diário e a conversão alimentar, estimando-se redução de 6,93 g e acréscimo de 43,15 g/unidade percentual de casca adicionada ao concentrado, respectivamente. O menor consumo de NDT, associado à menor digestibilidade da MS e dos nutrientes, foi o principal responsável pela redução no ganho de peso dos animais que receberam dietas contendo casca de café na ração concentrada. Embora a análise de variância tenha demonstrado tendência linear (Tabela 5), observou-se pequena redução no ganho de peso até o nível de $17,5 \%$ de casca de café, de modo que a redução mais acentuada ocorreu com a inclusão de $26,25 \%$ deste resíduo. Ao avaliarem a inclusão de casca de café na dieta de novilhos mestiços Holandês-Zebu em substituição a $0,10,20,30$ e $40 \%$ do milho desintegrado com palha e sabugo (MDPS) da ração concentrada, Barcelos et al. (1997) também verificaram comportamento semelhante

Tabela 4 - Valores médios dos coeficientes de digestibilidade (CD) e valores observados de NDT, de acordo com os níveis de casca de café na ração concentrada (com base na MS), coeficiente de variação (CV) e equações de regressão

Table 4 - Average values of digestibility coefficients $(D C)$ and observed TDN (TDN $O B S$ ) in response to different coffee hulls levels on concentrate (DM basis), coefficients of variation (CV), and regression equations

\begin{tabular}{|c|c|c|c|c|c|c|}
\hline \multirow[t]{2}{*}{ Itens } & \multicolumn{4}{|c|}{$\begin{array}{c}\text { Dieta } \\
\text { Diet }\end{array}$} & \multirow{2}{*}{$\begin{array}{l}\text { CV } \\
\%\end{array}$} & \multirow[t]{2}{*}{$\begin{array}{c}\text { Equação de regressão } \\
\text { Regression equation }\end{array}$} \\
\hline & 0 & 8,75 & 17,5 & 26,25 & & \\
\hline CDMS (DCDM) & 73,6 & 69,6 & 65,8 & 63,4 & 2,9 & $\hat{\mathrm{Y}}=73,31-0,3955 \mathrm{X}\left(\mathrm{r}^{2}=0,99\right)$ \\
\hline CDMO (DCOM) & 74,3 & 70,4 & 66,7 & 64,4 & 2,9 & $\hat{\mathrm{Y}}=73,98-0,3826 \mathrm{X}\left(\mathrm{r}^{2}=0,99\right)$ \\
\hline CDPB (DCCP) & 73,0 & 68,1 & 64,3 & 63,9 & 3,7 & $\hat{\mathrm{Y}}=72,02-0,3558 \mathrm{X}\left(\mathrm{r}^{2}=0,90\right)$ \\
\hline CDEE (DCEE) & 79,4 & 69,8 & 67,5 & 69,4 & 7,3 & $\hat{\mathrm{Y}}=76,41-0,3710 \mathrm{X}\left(\mathrm{r}^{2}=0,61\right)$ \\
\hline CDCT (DCTC) & 74,5 & 70,8 & 67,2 & 64,4 & 3,0 & $\hat{\mathrm{Y}}=74,31-0,3874 \mathrm{X}\left(\mathrm{r}^{2}=0,99\right)$ \\
\hline CDFDN (DCNDF) & 68,7 & 64,9 & 61,5 & 58,9 & 4,7 & $\hat{\mathrm{Y}}=68,46-0,3770 \mathrm{X}\left(\mathrm{r}^{2}=0,99\right)$ \\
\hline CDCNF (DCNFC) & 83,9 & 81,4 & 78,6 & 76,6 & 3,1 & $\hat{\mathrm{Y}}=83,85-0,2822 \mathrm{X}\left(\mathrm{r}^{2}=0,99\right)$ \\
\hline $\mathrm{NDT}^{1}(T D N)$ & 71,8 & 67,4 & 63,8 & 61,8 & 2,9 & $\hat{\mathrm{Y}}=71,24-0,3836 \mathrm{X}\left(\mathrm{r}^{2}=0,98\right)$ \\
\hline
\end{tabular}

\footnotetext{
1 Valores em porcentagem da MS (Values in percentage of dry matter).
} 
Tabela 5 - Médias para o peso vivo (PV) inicial e final, ganho de peso diário (GPD) e conversão alimentar (CA), de acordo com os teores de casca de café na ração concentrada (com base na MS), com suas respectivas equações de regressão

Table 5 - Means of initial body weight, final body weight, daily weight gain and feed conversion in response to different coffee hulls levels on concentrate (DM basis), coefficient of variation, and regression equations

\begin{tabular}{|c|c|c|c|c|c|c|}
\hline \multirow[t]{2}{*}{ Itens } & \multicolumn{4}{|c|}{$\begin{array}{l}\text { Dieta } \\
\text { Diet }\end{array}$} & \multirow{2}{*}{$\begin{array}{l}\text { CV } \\
\% \\
\end{array}$} & \multirow[t]{2}{*}{$\begin{array}{l}\text { Equação de regressão } \\
\text { Regression equation }\end{array}$} \\
\hline & 0 & 8,75 & 17,5 & 26,25 & & \\
\hline $\begin{array}{l}\mathrm{PV} \text { inicial }(\mathrm{kg}) \\
\text { Initial body weight }\end{array}$ & 206,7 & 200,8 & 197,8 & 199,5 & - & - \\
\hline $\begin{array}{l}\mathrm{PV} \text { final }(\mathrm{kg}) \\
\text { Final body weight }\end{array}$ & 296,7 & 282,3 & 282,3 & 271,5 & - & $\hat{x}$ \\
\hline $\begin{array}{l}\mathrm{GPD}(\mathrm{g} / \mathrm{dia}) \\
\text { Daily weight gain }\end{array}$ & 1071 & 970 & 1005 & 857 & 10,1 & $\hat{\mathrm{Y}}=1067,26-6,9387 \mathrm{X}\left(\mathrm{r}^{2}=0,76\right)$ \\
\hline $\begin{array}{l}\mathrm{CA} \\
\text { Feed conversion }\end{array}$ & 6,66 & 6,72 & 6,57 & 7,98 & 12,1 & $\hat{Y}=6,41-0,0432 X\left(r^{2}=0,54\right)$ \\
\hline
\end{tabular}

Tabela 6 - Custos com alimentação, receita bruta, margem bruta e custo por arroba produzida, de acordo com os teores de casca de café na ração concentrada

Table 6 - Feeding costs, gross income, gross margin and cost of production of $30 \mathrm{~kg}$ body weight in response to different coffee hulls levels on concentrate (DM basis)

Itens

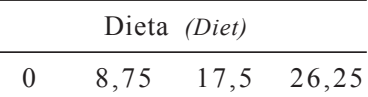

Despesas (Expense)

Volumoso $^{1}$ (Forage)

Pré-secado $(\mathrm{kg} / \mathrm{nov} / \mathrm{dia})$

Haylage ( $\mathrm{kg} / \mathrm{heifers/day)}$

Custo do pré-secado (R $\$ /$ nov/dia)

Haylage cost (R\$heifers/day)

Concentrado $^{1}$ (Concentrate $^{2}$ )

Farelo de soja $(\mathrm{kg} / \mathrm{nov} / \mathrm{dia})$

Soybean meal (kg/heifers/day)

Custo $(\mathrm{R} \$ /$ nov/dia)

Cost (R\$/heifers/day)

Fubá de milho $(\mathrm{kg} / \mathrm{nov} / \mathrm{dia})$

Ground corn (kg/heifers/day)

Custo $(\mathrm{R} \$ /$ nov/dia)

Cost (R\$/heifers/day)

Casca de café (g/nov/dia)

Coffee hulls (g/heifers/day)

Custo $(\mathrm{R} \$ /$ nov/dia)

Cost ( $R \$ /$ heifers/day)

Suplemento mineral (g/nov/dia)

Mineral supplement (g/heifers/day)

Custo do suplemento (R $\$ /$ nov/dia)

Supplement cost (R\$/heifers/day)

$\begin{array}{lllll}\text { Custo do concentrado (R/nov/dia) } & 1,60 & 1,36 & 1,29 & 1,19\end{array}$

Concentrate cost (R\$/heifers/day)

Custo da dieta $(\mathrm{R} \$ /$ nov/dia)

Diet cost ( $R \$ /$ heifers/day)

Custo por ganho de peso $(\mathrm{R} \$ / \mathrm{kg})$

Weight gain cost ( $R \$ / \mathrm{kg})$

Receita bruta (Gross income)

Ganho por@(R\$) ${ }^{1,2}$

Income $(R \$ / 30 \mathrm{~kg})$

Renda total (R\$)

Total income, $R \$$

Relação custo da dieta/receita (\%) $\quad 72,5 \quad 69,7 \quad 65,3 \quad 73,1$

Diet cost/income ratio (\%)

Margem bruta $(\mathrm{R} \$ /$ nov/dia $)$

Gross margin ( $\$$ /cow/day)

\footnotetext{
${ }^{1}$ Preços praticados na região de Viçosa/MG em abril de 2003 (Prices scollects in Viçosa/MG, 04/2003) 1,2 Fêmeas leiteiras de bom potencial genético (Dairy heifers with good genetic potential).
}

para ganho de peso médio, com valores de 1,$10 ; 1,04 ; 1,03 ; 1,05$ e $0,88 \mathrm{~kg} /$ dia, respectivamente.

Os custos com alimentação das novilhas (Tabela 6) reduziram gradativamente com a inclusão de casca de café nas dietas, provavelmente como efeito principal da substituição do milho pela casca. Pequena parte das diferenças resultou das variações no consumo médio de MS das dietas, como demonstrado na Tabela 4.

Apesar de os gastos com alimentação dos animais terem sidos reduzidos com a adição de casca de café, a dieta com $26,25 \%$ de casca foi a que apresentou maior custo por arroba produzida. Todavia, a adição deste resíduo em até $17,5 \%$, além de ter contribuído favoravelmente para redução das despesas com alimentação, proporcionou o menor custo de ganho de peso.

Os gastos com alimentação dos animais foram elevados e representaram, em média, 72,2 e $64,9 \%$ do total das receitas que poderiam ser obtidas utilizando-se as dietas com $0 \mathrm{e}$ $17,5 \%$ de casca de café, respectivamente. Em rebanhos mais produtivos, os alimentos concentrados constituem um dos fatores mais onerosos do sistema de produção (Pereira \& Correa, 2001; Santos, 2001). A avaliação de alimentos alternativos que possam substituir ingredientes comumente utilizados na formulação de rações concentradas, com a definição do real valor nutritivo para diferentes categorias animais e níveis de produção, pode contribuir para a melhoria dos índices de produção dos rebanhos, proporcionando maior renda para o produtor rural.

\section{Conclusões}

Apesar de os consumos de MS, MO, FDN e de PB não terem sido alterados, a redução da ingestão de carboidratos não-fibrosos e da digestibilidade da MS e dos nutrientes da dieta proporcionaram menor ingestão de NDT para os animais que consumiram dietas contendo casca de café. 
A casca de café promoveu decréscimo de $6,94 \mathrm{~g} /$ dia no ganho de peso das novilhas por unidade percentual de casca de café adicionada ao concentrado. Todavia, a inclusão de até $17,5 \%$ deste resíduo em substituição ao milho da ração concentrada $(7,0 \%$ na MS da dieta) pode ser considerada benéfica, pois gerou a melhor margem bruta, proporcionando ganhos médios diários próximos aos obtidos com os teores de 0 e $8,75 \%$ de casca de café na ração concentrada.

\section{Literatura Citada}

ALLEN, M.S.; MERTENS, D.R. Evaluating constraints on fiber digestion by rumen microbes. Journal Nutrition, v.118, p. 261-270, 1987.

BAIÃO, A.F. Desempenho de novilhos nelore suplementados a pasto com diferentes níveis de concentrado. Lavras, MG: Universidade Federal de Lavras, 2002. 43p. Dissertação (Mestrado em Zootecnia) Universidade Federal de Lavras, 2002.

BARCELOS, A.F.; ANDRADE, I.F.; VON TIESENHAUSEN, I.M.E.V. et al. Aproveitamento da casca de café na alimentação de novilhos confinados - resultados do primeiro ano. Revista Brasileira de Zootecnia, v.26, n.6, p.1208-1214, 1997.

BARCELOS, A.F.; PAIVA, P.C.A.; PÉREZ, J.R.O. et al. Fatores antinutricionais da casca e da polpa desidratada de café (Coffea arábica L.) armazenadas em diferentes períodos. Revista Brasileira de Zootecnia, v.30, n.4, p.1325-1331, 2001.

BÁRTHOLO, G.F.; MAGALHÃES FILHO, A.A.R.; GUIMARÃES, P.T.G. et al. Cuidados na colheita, no preparo e no armazenamento do café. Informe Agropecuário, v.14, n.162, p.33-44, 1989.

COCHRAN, R.C.; ADAMS, D.C.; WALLACE, J.D. et. al. Predicting digestibility diets with internal markers: evaluation of four potential markers. Journal of Animal Science, v.63, p.1476483, 1986.

MERTENS, D.R. Regulation of forage intake. In: FAHEY JR., G.C. (Ed.) Forage quality, evaluation and utilization. Madison: 1994. p.450-493.

NATIONAL RESEARCH COUNCIL - NRC. Nutrient requirements of dairy cattle. 6.ed. Washington D.C.: National Academy of Science, 1989. 158p.

NATIONAL RESEARCH COUNCIL - NRC. Nutrient requirements of dairy cattle. 7.ed. Washington, D.C.: National Academy Press, 2001. 381p.

OLIVEIRA, J.P.; ANDRADE, I.F.; SANTOS, R.A.S. et al. Estimativa das frações nitrogenadas do feno de coastcroos, cama de frangos e casca de café, pelo sistema cncps. In: REUNIÃO ANUAL DA SOCIEDADE BRASILEIRA DE ZOOOTECNIA, 38, 2001, Piracicaba. Anais... Piracicaba:SBZ/Macromedia, [2001]. CD-ROM. Nutrição de Ruminantes.

PEREIRA, M.N.; CORREA, C.E.S. Manejo dos sistemas de produção de leite em confinamento. In: SUSTENTABILIDADE DE SISTEMAS DE PRODUÇÃO DE LEITE A PASTO E EM CONFINAMENTO, 2001, Juiz de Fora. Anais... Juiz de Fora: Embrapa Gado de Leite, 2001. p.163.
RODRIGUES FILHO, J.A.; GONÇALVES, C.A.; CAMARÃO, A.P. et al. Suplementação alimentar de novilhas de origem leiteira em pastagem de Panicum maximum cv Tobiatã. In. REUNIÃO ANUAL DA SOCIEDADE BRASILEIRA DE ZOOTECNIA, 39 , 2002, Recife. Anais... Recife: SBZ/Gmosis, [2002]. CDROM. Nutrição de Ruminantes.

SNIFFEN, C.J.; O'CONNOR, J.D.; VAN SOEST, P.S. et. al. A net carbohydrate and protein system for evaluating cattle diets. II. Carbohydrate and protein availability. Journal of Animal Science, v.70, n.11, p.3562-3577, 1992.

SANTOS, F.A.P. Manejo dos sistemas de produção de leite a pasto. In: SUSTENTABILIDADE DE SISTEMAS DE PRODUÇÃO DE LEITE A PASTO E EM CONFINAMENTO, 2001, Juiz de Fora Anais... Juiz de Fora: Embrapa Gado de Leite, 2001. p.163.

SILVA, D.J.; QUEIROZ, A.C. Análise de alimentos: métodos químicos e biológicos. 3.ed. Viçosa, MG: Universidade Federal de Viçosa, 2002. 235p.

SOUZA, A.L.; GARCIA, R.; PEREIRA, O.G. et al. Valor nutritivo da casca de café tratada com amônia anidra. Revista Ceres, v.49, n.286, p.669-681, 2002.

SOUZA, A.L.; BERNARDINO, F.S.; GARCIA, R. et al. Valor nutritivo de silagem de capim-elefante (Pennisetum purpureum Schum.) com diferentes níveis de casca de café. Revista Brasileira de Zootecnia, v.32, n.4, p.828-823, 2003.

SOUZA, A.L.; GARCIA, R.; BERNARDINO, F.S. et al. Casca de café em dietas de carneiros: consumo e digestibilidade. Revista Brasileira de Zootecnia, v.33, n.6, p.2170-2176, 2004 (supl. 2).

UNIVERSIDADE FEDERAL DE VIÇOSA - UFV. Sistema de análises estatísticas e genéticas - SAEG. Versão 7.1. Viçosa, MG: 1997. 150p. (Manual do usuário).

VALADARES FILHO, S.C.; ROCHA JR., V.R.; CAPPELLE, E.R. Tabelas brasileiras de composição de alimentos para bovinos. Viçosa, MG: Universidade Federal de Viçosa, 2001. 297p.

VARGAS, E.; CABEZAS, M.T.; MURILO, B. et al. Efecto de altos niveles de pulpa de café deshidratada sobre el crecimiento y adaptación de novillos jóvenes. Archivos Latinoamericanos de Nutrición, v.32, n.4, p.972-989, 1982.

VILELA, F.G. Uso da casca de café melosa em diferentes níveis na alimentação de novilhos confinados. Lavras, MG: Universidade Federal de Lavras, 1999. 46p. Dissertação (Mestrado em Zootecnia) - Universidade Federal de Lavras, 1999.

WEISS, W.P.; CONRAD, H.R.; PIERRE, N.R. St. A theoreticallybased model for predicting total digestible nutrient values forages and concentrates. Animal Feed Science and Technology, v.39, p.95-110, 1992.
Recebido: 10/10/04 Aprovado:29/08/05 